\title{
HHV8 K2 Gene
}

National Cancer Institute

\section{Source}

National Cancer Institute. HHV8 K2 Gene. NCI Thesaurus. Code C114502.

HHV8 K2, which encodes viral interleukin- 6 homolog protein, plays a role in cell proliferation, cell differentiation and the prevention of apoptosis. 